normal glucose tolerance for more than 18 months after the initial diagnosis and in the presence of continued prednisolone treatment. Moreover, the patient had no family history of diabetes and no detectable islet cell antibodies at the time of diagnosis.

We are left with the possibility that diabetes was induced by cyclosporin. Though cyclosporin has prevented the development of insulin dependent diabetes in spontaneously diabetic animal models, it inhibited $\beta$ cell proinsulin biosynthesis and insulin release in cultured mouse and human pancreatic islets. ${ }^{7}$ The association of $\mathrm{C}$ peptide depression with high blood cyclosporin concentrations in our patient may be relevant.

The suggestion that cyclosporin may be associated with the appearance of post-transplantation diabetes in renal allograft recipients ${ }^{2}$ has not been confirmed by other workers, who found that this occurs regardless of the immunosuppressive regimen and whether or not cyclosporin is included. ${ }^{3}$

We suggest that dose related $\beta$ cell toxicity of cyclosporin A may be a risk in recipients of the drug. This phenomenon appears to be reversible by reducing the dose and underlines the need for careful monitoring of drug and glucose'concentrations.
We thank Professor Harry Keen for his help and encouragement. We also thank Dr J D Teale, of the department of clinical biochemistry at St Luke's Hospital, Guildford, for the C peptide estimations, and Dr D Vergani, department of immunology, King's College Hospital, London, for measuring islet cell antibodies.

\section{References}

1 Nerup J, Bendtzen K, Mandrup-Poulsen T. A role for cyclosporin A in the treatment of insulin dependent diabetes mellitus? Diabetic Medicine 1985;2:441-6.

2 Yagisawa T, Takahashi K, Teraoka S, Toma $\mathrm{H}$, Agishi T, Ota $\mathrm{K}$. Deterioration in glucose metabolism in ciclosporin-treated kidney transplant recipients and rats. Transplant Proc (in press).

3 Weisz A, Ratner R. Factors in renal transplant-induced diabetes. Diabetes 1986;35(suppl 1):72A. 4 Hampton S. Radioimmunoassay for $C$ peptide. University of Surrey, 1983.

5 Rim RA, Mandarino LJ, Gerich JE. Corisol-induced in suppression of glucose production and stimulation of glucose utilization due to a postreceptor defect of insulin action. $\mathcal{F}$ Clin Endocrinol Metab 1982;54:131-8.

6 Cohen P, Barzilai N, Barzilai D, Karnieli E. Correlation between insulin clearance and insulin responsiveness: studies in normal, obese, hyperthyroid, and Cushing's syndrome patients. Metabolism 1986;35:744-9.

7 Nielsen JH, Mandrup-Poulsen T, Nerup J. Direct effects of cyclosporin A on human pancreatic B-cells. Diabetes 1986;35:1049-52.

(Accepted 11 December 1986)

\title{
Detection of venom by enzyme linked immunosorbent assay (ELISA) in patients bitten by snakes in Thailand
}

\author{
KAMOLRAT SILAMUT, MAY HO, SORNCHAI LOOAREESUWAN, CHAISIN VIRAVAN, \\ VANAPORN WUTHIEKANUN, DAVID A WARRELL
}

\begin{abstract}
The ability of an enzyme linked immunosorbent assay (ELISA) to detect venom was evaluated in $\mathbf{2 5 1}$ patients bitten by four of the commonest poisonous snakes in Thailand. Serum was tested only from patients who brought the snakes that had bitten them. About one third of all bitten patients had detectable venom antigenaemia, though a smaller proportion were symptomatic. Serum venom concentrations on admission correlated with the severity of clinical manifestations. The test was sensitive and specific even for specimens that had been collected and stored under suboptimal conditions. The technique is suitable for forensic use in cases of suspected snakebite.

The combination of snake identification and venom antigen detection should be a more reliable means of studying the epidemiology of snakebite than the measurement of venom antibodies in a population.
\end{abstract}

\section{Introduction}

Snakebite is a common medical emergency in many tropical countries. Most patients do not provide conclusive evidence of the

\footnotetext{
Hospital for Tropical Diseases, Faculty of Tropical Medicine, Mahidol University, Bangkok 10400, Thailand

KAMOLRAT SILAMUT, MSC, medical laboratory technologist MAY HO, MD, FRCP(C), Wellcome fellow

SORNCHAI LOOAREESUWAN, MD, DTM\&H, associate professor CHAISIN VIRAVAN, MD, DTM\&H, associate professor

VANAPORN WUTHIEKANUN, BSC, medical laboratory technologist DAVID A WARRELL, DM, FRCP, consultant

Correspondence and requests for reprints to: Dr.Ho.
}

species that bit them by bringing the dead snake with them to the hospital. In some instances, even when the snakes are brought, the medical staff are unable to identify them. Clinical diagnosis based on signs and symptoms may be very misleading. For example, in Thailand the Malayan pit viper (Calloselasma rhodostoma), green pi viper (Trimeresurus albolabris), and Russell's viper (Vipera russelli), all produce a similar syndrome of local swelling, spontaneous bleeding, and no blood clotting. In the absence of a dead snake or in a case of mistaken identification the wrong monospecific antivenom may be given to the patient. Identification of the snake that bit them is therefore of the utmost importance for the proper management of patients with snakebite.

The application of the enzyme linked immunosorbent assay (ELISA) to identifying the biting species in cases of snakebite was first described by Theakston et al. ${ }^{1}$ Since then diagnostic kits based on the assay and prepared by the Commonwealth Serum Laboratory in Australia have been used with some success. ${ }^{23}$ ELISA has also been used in snakebite studies in Malaysia, Burma, Thailand, the United States, and Ecuador..$^{49}$ Modifications of the original test have been found to be necessary to minimise the problems of nonspecific reactivity and cross reactivity encountered commonly with serum specimens from rural populations in the tropics. ${ }^{10}$

The present study was undertaken to determine the incidence of systemic envenoming among snakebite victims and to validate the modified ELISA procedure ${ }^{11}$ for the large scale testing of serum samples collected by paramedical staff in rural Thailand.

\section{Patients and methods}

As part of a countrywide survey conducted in Thailand to determine the distribution of snake species causing morbidity and mortality the nursing staff in provincial hospitals were requested to record on standard forms the history and clinical signs of every patient who presented with snakebite. The signs sought were local swelling; bleeding from the site of the bite and gums 
or blood in the saliva; and hypotension and neurotoxic signs such as ptosis, ophthalmoplegia, and respiratory paralysis. A simple clotting test was performed by observing whether $2 \mathrm{ml}$ venous blood in a clean, dry glass tube clotted after standing for 20 minutes at ambient temperature $\left(25-35^{\circ} \mathrm{C}\right)$. Another $5 \mathrm{ml}$ blood was allowed to clot for six hours at ambient temperature. Where possible, serum was separated by centrifugation. In small hospitals that did not have a centrifuge serum was poured off after the clot had separated. Serum was stored at $4^{\circ} \mathrm{C}$ (or $-20^{\circ} \mathrm{C}$ when available) until it was assayed in Bangkok. Only those patients who were bitten by $C$ rhodostoma, $T$ albolabris, $V$ russelli, or Naja kaouthia, the monocellate Thai cobra, and who brought dead snakes for identification were included in the study. Dead snakes were labelled and preserved in $10 \%$ formalin and later identified by one of us (DAW)

\section{ELISA TEST PROCEDURE}

The ELISA to detect venom was performed as described. ${ }^{11}$ Briefly, alternate wells of polystyrene microtitre plates (Nunc Immuno Plate I, Kamstrup, Denmark) were coated with 1-2 $\mu \mathrm{g}$ specific hyperimmune IgG/ $\mathrm{ml}$ and normal rabbit IgG in bicarbonate and carbonate buffer at pH 9:6. After overnight incubation at $4^{\circ} \mathrm{C}$ the plates were coated with $1 \%$ bovine serum albumin for one hour. Twenty microlitres of the serum samples was added to $180 \mu \mathrm{l}$ phosphate buffered saline containing $0.05 \%$ Tween in each well, and the plate was incubated at room temperature for four hours. Conjugate labelled with alkaline phosphatase at $1 / 500$ to $1 / 1000$ dilution was then added and the plate kept at $4^{\circ} \mathrm{C}$ overnight. The reaction with the substrate $p$-nitrophenyl phosphate in diethanolamine buffer at $\mathrm{pH} 9 \cdot 8$ was allowed to proceed for 30 minutes at room temperature. Absorbance values at $405 \mathrm{~nm}$ were determined with a Titertek Multiscan spectrophotometer (Flow Laboratories, Irvine, Ayrshire). The absorbance values of wells coated with normal rabbit IgG were subtracted from those of wells coated with specific hyperimmune IgG. The venom concentrations were read off a standard curve prepared by including samples of known amounts of venom in phosphate buffered saline and Tween with $10 \%$ normal human serum.

To determine the sensitivity and specificity of the ELISA, serum from 106 healthy subjects in Trang province, southern Thailand, was tested for the presence of venom from the four snakes. In addition, serum in the study that was found to be positive for the venom corresponding to the snake brought for identification was tested for the other three venoms.

\section{Results}

We studied 251 patients who presented to 17 hospitals in 13 provinces with a history of snakebite and brought the dead snakes for identification. The ratio of men to women was 159 to 92 with a mean age of 34 (range 2-86) years. The preponderance of men was explained by the large number of rice farmers and rubber planters bitten by the vipers $V$ russelli and $C$ rhodostoma while working in the fields and plantations.

Clinical signs-The table summarises the clinical signs. Among the patients bitten by vipers swelling was significantly more common after bites by $C$ rhodostoma and $T$ albolabris than after bites by $V$ russelli. Spontaneous

Clinical signs on admission of 251 patients bitten by the four commonest snakes in Thailand. (Values are numbers (\%) of patients)

\begin{tabular}{|c|c|c|c|c|}
\hline & $\begin{array}{c}\text { Calloselasma } \\
\text { rhodostoma } \\
\quad(\mathrm{n}=99)\end{array}$ & $\begin{array}{l}\text { Vipera } \\
\text { russelli } \\
(\mathrm{n}=68)\end{array}$ & $\begin{array}{c}\text { Trimeresurus } \\
\text { albolabris } \\
(\mathrm{n}=68)\end{array}$ & $\begin{array}{c}\text { Naja } \\
\text { kaouthia } \\
(\mathrm{n}=16)\end{array}$ \\
\hline $\begin{array}{l}\text { Swelling } \\
\text { Spontaneous bleeding } \\
\text { Blood not clotting } \\
\text { Neurotoxic signs }\end{array}$ & $\begin{array}{c}73(74) \\
4(4) \\
14(14) \\
\text { Not applicable }\end{array}$ & $\begin{array}{c}29(43) \\
2(3) \\
14(21) \\
\text { Not applicable }\end{array}$ & $\begin{array}{c}55(81) \\
1(1) \\
7(10) \\
\text { Not applicable }\end{array}$ & $\begin{array}{c}8(50) \\
\text { Not applicable } \\
\text { Not applicable } \\
1(6)\end{array}$ \\
\hline
\end{tabular}

bleeding was rare, and blood did not clot in only a few patients. Neurotoxic signs after bites by $N$ kaouthia were rarely reported, and no patient suffered lifethreatening respiratory problems. Most patients (201 of $251 ; 80 \%$ ) were seen within two hours of being bitten.

Standardisation of venom detection assays-The mean (SD) absorbance values of 106 normal serum samples tested for venom from $C$ rhodostoma, $T$ albolabris, $V$ russelli, and $N$ kaouthia were $0.006(0.020), 0.027(0.029)$, $0.004(0.016)$, and $0.003(0.015)$, respectively. With the mean plus two SD as the cut off point the assays had a sensitivity of $1,2,1$, and $1 \mathrm{ng} /$ well, or 10 , 20,10 , and $10 \mathrm{ng} / \mathrm{ml}$ as the serum samples were tested at dilution of
1/10. No cross reactivity among the four venoms was shown, but the absorbance values of a few normal serum samples exceeded the cut off point. The specificities of the venom detection assays were thus $94 \%, 92 \%$, $96 \%$, and $97 \%$, respectively. The coefficients of variation of the assays were from $8 \%$ to $12 \%$.

Prevalence of systemic envenoming-Circulating venom was detected in 40 of 99 patients ( $40 \%$ ) bitten by $C$ rhodostoma, 24 of 68 patients ( $35 \%$ ) bitten by $V$ russelli, 26 of $68(38 \%)$ bitten by $T$ albolabris, and five of $16(31 \%)$ by $N$ kaouthia. Not all patients who had circulating venom, however, showed clinical signs of systemic envenoming. The proportion of symptomatic patients was highest among those bitten by $V$ russelli $(39 / 68 ; 57 \%)$, followed by those bitten by $C$ rhodostoma $(43 / 99 ; 43 \%), T$ albolabris $(16 / 68 ; 24 \%)$, and $N$ kaouthia $(4 / 16 ; 25 \%)$.

Correlation of clinical signs with concentration of venom on admission-The figure shows the concentration of venom on admission of patients with and without clinical signs. The mean (SE) concentrations of venom for patients

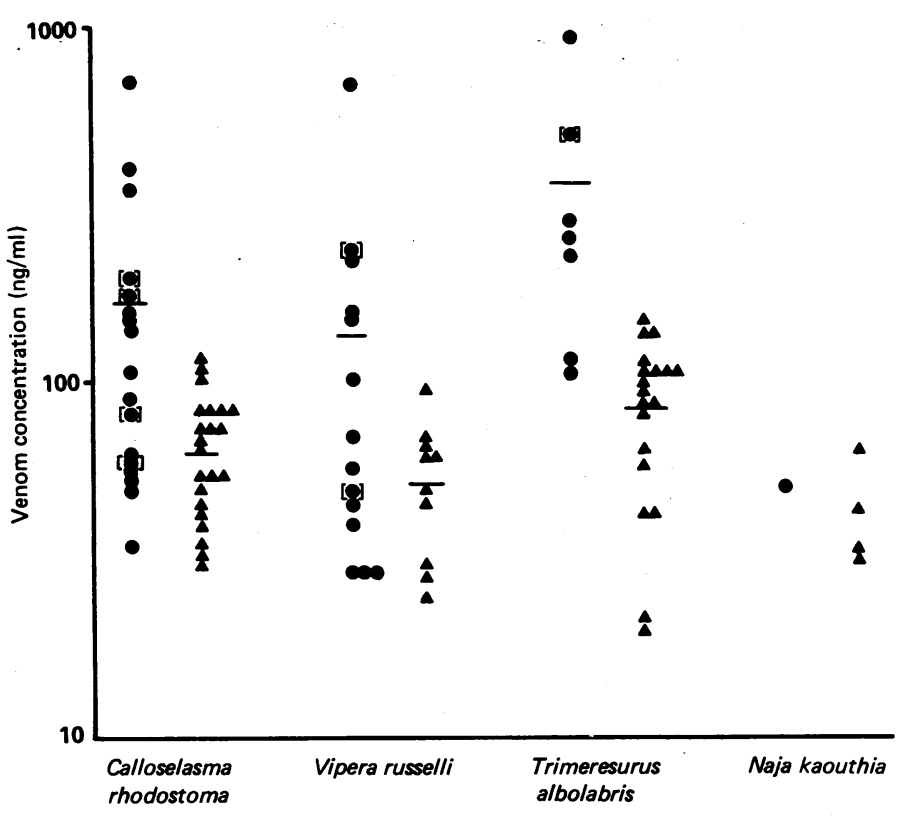

Serum venom concentrations in patients admitted with $(O)$ and without $(\Delta)$ signs of systemic envenoming.

whose blood did not clot after being bitten by $C$ rhodostoma, $V$ russelli, and $T$ albolabris were $165(40) \mathrm{ng} / \mathrm{ml}, 130(43) \mathrm{ng} / \mathrm{ml}$, and $318(99) \mathrm{ng} / \mathrm{ml}$, respectively. These were significantly higher than the mean venom concentrations of $66(5) \mathrm{ng} / \mathrm{ml}, 52(7) \mathrm{ng} / \mathrm{ml}$, and $83(8) \mathrm{ng} / \mathrm{ml}$ in patients who did not show any gross clotting abnormality $(\mathrm{p}<0.02, \mathrm{p}<0.05$, and $\mathrm{p}<0.02$, respectively). The number of patients who showed systemic evenoming after being bitten by $N$ kaouthia was too small for statistical analysis.

\section{Discussion}

To our knowledge this study is the first large scale use of the ELISA for detecting venom in victims of snakebite. Specificity was established by using serum only from patients who brought the snake that had bitten them. In every case the ELISA was both sensitive and specific for identifying the snake species. Some of the samples were left at $4^{\circ} \mathrm{C}$ for several months while other specimens were mistakenly frozen as whole blood. The possibility of nonspecific reactions arising from improper storage of specimens was minimised by the inclusion of normal IgG coated wells as controls. We have shown previously that the addition of $1 \%$ normal serum appropriate to the animal in which the reagents were raised to the diluent for both serum and conjugate also reduces non-specific reactivity. ${ }^{10}$

Before immunodiagnosis the prevalence of systemic envenoming has always been determined by the presence or absence of clinical signs. People bitten by snakes, however, may develop symptoms and signs that are attributable not to venom but rather to fear or the effects of non-specific treatment. On the other hand, as systemic 
signs after envenoming by some species of snake can be delayed for up to 72 hours, " many patients with systemic envenoming would have been missed unless they had been admitted to hospital for observation. The use of the ELISA allows better assessment of the prevalence of envenoming and hence the importance of snakebite as a medical problem. It may provide a reliable indication for antivenom treatment and indicate if adequate amounts have been given. Venom from snakes and other animals has, on occasions, been used for suicide or even murder, ${ }^{12-15}$ and snakebite may be suggested as a cause of death. ${ }^{16}$ In such cases diagnosis by ELISA would be valuable to forensic pathologists.

The serum venom concentration on admission generally correlated well with clinical manifestations among patients bitten by one of the three vipers, but the serum venom concentration was obviously not the only determinant. The presence of systemic signs is also related to the duration of the period between being bitten and hospital admission" and, in the case of coagulability, the age of the victim, as the turnover of clotting factors is much more rapid in children. The time element may not be as important with venoms that have a rapid action-for example, the venom of $V$ russelli, which acts on several steps of the clotting cascade, as opposed to the purely defibrinogenating effects of the venoms of $C$ rhodostoma and $T$ albolabris. Envenoming by $N$ kaouthia was mild in the five patients in this study, but in a previous study we have shown that the occurrence of neurotoxic symptoms did correlate with serum venom concentrations on admission. ${ }^{?}$

The results of this study suggest that the combination of snake preservation and identification and venom antigen detection may be much more accurate for studying the epidemiology of snakebite than the measurement of antibodies in a population. ${ }^{17}$ Non-specific and cross reactivity in antibody detection assays is much more difficult to overcome than in venom detection assays and at times may represent true cross reactions between venom and antibodies to other toxins in the environment. The clinical value of ELISA would be greatly increased if it could be carried out more simply and rapidly. Diagnostic adaptations of ELISA for detecting venom that require five to 30 minutes have been reported, ${ }^{418}$ but their reliability during routine use needs further evaluation.

We are grateful to the medical and nursing staff of all the hospitals that participated in the national snake survey, in particular Dr Udom Veeravat of Bangphli Hospital, Dr Krit Hiranras of Lopburi Hospital, Dr Saroj Kongprasard of Baanmi Hospital, DrChul Karnchanachetanee of Chaopraya Aphaiphubet Hospital, Dr Suthas Vejcho and Miss Nilubon Krisanaphan of Trang Hospital, Dr Surasak Laosuwan of Chainat Hospital, and Dr Ulrich Juzi of Manorom Hospital. We thank Khun Nucharee Cholvilai for preparing the manuscript. This study is part of the Wellcome-Mahidol University Oxford tropical medicine research programme funded by the Wellcome Trust of Great Britain.

\section{References}

1 Theakston RDG, Lloyd-Jones MJ, Reid HA. Micro-ELISA for detecting and assaying snake venom and venom antibody. Lancet 1977;ii:639-41.

2 Chandler HM, Hurrell JGR. A new enzyme immunoassay system suitable for field use and its application in a snake venom detection kit. Clin Chim Acta 1982;121:225-30.

3 Hurrell JGR, Chandler HW. Capillary enzyme immunoassay field kits for the detection of snake venom in clinical specimens. A review of two years' use. Med $\mathcal{J}$ Aust 1982;ii:236-7.

4 Dhaliwal JS, Lim TW, Sukumaran KD. A double antibody sandwich micro-ELISA kit for the rapid diagnosis of snake bite. Southeast Asian Y Trop Med Public Health 1983;14:367-73.

$5 \mathrm{Khin}-\mathrm{Ohn}$-Lwin, Aye-Aye-Myint. The use of enzyme-linked immunosorbent assay (ELISA) in detection of Russell's viper venom in body fluid. The Snake 1982;14:77-82.

$6 \mathrm{Khin}-\mathrm{Ohn}$-Lwin, Aye-Aye-Myint, Tun-Pe, Theingie-Nwe, Min-Naing. Russell's viper venom levels in serum of snake bite victims in Burma. Trans $R$ Soc Trop Med Hyg 1984;78: 165-8.

7 Viravan C, Veeravat U, Warrell MJ, Theakston RDG, Warrell DA. ELISA confirmation of acute and past envenoming by the monocellate Thai cobra (Naja kaouthia). Am 7 Trop Med Hyg 1986;35:173-81.

8 Minton SA, Weinstein SA, Wilde CE. An enzyme linked immunoassay for detection of North American pit viper venoms. Clin Toxicol 1984;22:303-16.

9 Theakston RDG, Reid HA, Larrick JW, Kaplan J, Yost JA. Snake venom antibodies in Ecuadorian Indians. I Trop Med Hyg 1981;84:199-202.

$10 \mathrm{Ho} \mathrm{M,} \mathrm{Warrell} \mathrm{MJ,} \mathrm{Warrell} \mathrm{DA,} \mathrm{Bidwell} \mathrm{D,} \mathrm{Voller} \mathrm{A.} \mathrm{A} \mathrm{critical} \mathrm{reappraisal} \mathrm{of} \mathrm{the} \mathrm{use} \mathrm{of} \mathrm{enzyme-}$ linked immunosorbent assays in the study of snake bite. Toxicon 1986;24:211-21.

11 Ho M, Warrell DA, Looareesuwan S, et al. Clinical significance of venom antigen levels in patients envenomed by the Malayan pit viper (Calloselasma rhodostoma). Am $\mathcal{J}$ Trop Med Hyg 1986;35:579-87.

12 Fayrer J. Deaths from snake bites; a trial, condensed from the Sessions' Report. Indian Medical Gazette 1869;4:156-7.

13 Eaker DK, Karlsson E, Lic F, Rammer L, Saldeen T. Isolation of neurotoxin in a case of fatal cobra bite. I Forensic Sci 1986;16:96.

14 Knight B, Barclay A, Mann R. Suicide by injection of snake venom. I Forensic Sci 1977;10:141-5.

15 Yadlowski JM, Tu AT, Garriott JC, Norten LE. Suicide by snake venom injection. I Forensic Sci 1980;25:760-4.

16 Muelling RJ, Samson RF, Beven T. The precipitin test in elucidating the cause of death. Am $\mathcal{J}$ Clin Pathol 1957;28:489-94.

17 Pugh RNH, Theakston RDG. Incidence and mortality of snake bite in savanna Nigeria. Lancet 1980;ii:1181-3.

18 Coulter AR, Harris RD, Sutherland SK. Enzyme immunoassay for the rapid clinical identification of snake venom. Med J Aust 1980;i:433.

(Accepted 17 December 1986)

\section{YEARS AGO}

A new form of adulteration is likely before long to engage the attention of milk analysts and magistrates; indeed, we can only explain the fact that no prosecutions have as yet been undertaken on the supposition that grave doubts are entertained as to the probability of bringing this form of fraud within the letter of the existing Sale of Foods and Drugs Act. We allude to the rapidly increasing employment of so-called milk preservatives, with advertisements of which-sometimes occupying an entire page-the trade journals at present teem. They are not used by the great milk companies, nor, we have reason to believe, by farmers, at least to any extent; but they do undoubtedly find a ready sale among the smaller retail dealers. The explanation of the favourable reception they have met with is not far to seek; the yield of milk of any number of cows varies with the weather almost from day to day, and a dealer must regulate his minimum supply by the maximum demand likely to be made upon him by his customers. He thus, more often than not, has a surplus left on his hands every night. To those who go in for the butter business, and can afford to put up a separator, the amount of this surplus is immaterial; it is at once made into butter, and the skim milk sold as such or sent to piggeries. The smaller dealer, on the other hand, finds in the preservative the means of carrying over the excess of one day to the credit of the next. These proprietary nostrums are essentially compounds of boric (boracic) or salicylic acids, though bicarbonate of soda is also used. We do not pretend that any of these substances can be fairly described as "noxious drugs;" but it needs no argument to prove that anything which acts as a powerful therapeutic agent in disease cannot be absolutely inactive when habitually consumed in health. On this ground, their use is expressly prohibited in Germany, some of the American States, and in France, though in the latter country "salicylage" is still practised on an enormous scale, and many samples of Brittany butter actually glisten with crystals, probably mistaken by the purchaser for salt. A company in one of the southern counties is now sending out, in small brown jars, cream guaranteed to keep for a week, owing, as they pretend, to its purity, and its being obtained by means of the separator. Since, however, this ingenious and most useful apparatus merely saves the twelve, eighteen, or twenty-four hours that would have been required for raising the cream by the older methods, it is obvious that the extraordinary stability of the cream in question must be obtained by the addition of a preservative, in itself tasteless, but which deprives the cream of its natural delicate flavour. Another reprehensible practice is that of using colourings, the basis of which is anatto. The different kinds of cheese have so long been distinguished by conventional depth of artificial colouring - just as rum, brandy, and whiskey are, while gin is left of its natural transparency - that such a practice cannot be held to involve any fraud; and the same may be said of butter, which is more pleasant to the eye when yellow, though its quality is judged of by taste and smell. But the case is quite different with regard to milk, the richness of which is popularly estimated by the eye. Skimming and watering, if carried beyond very moderate limits, betray themselves by the blueness or translucency of the milk; but the addition of anatto gives a delusive semblance of richness to the poorest milk, and deprives the consumer of the only means in his power of distinguishing the most adulterated from the genuine article. Except in the case of a few breeds, as the pure Alderney cow, milk is white rather than yellow, and even in these the yellow colour is seen to be limited to the supernatant layer of cream, when the milk is viewed laterally in a glass; but if, as is alleged, the public expect milk to be yellow, the demand has been created by this objectionable because delusive practice, which is accordingly prohibited by law in the enlightened State of Massachusetts. (British Medical Foumal 1887;ii:733.) 